\title{
Covariation between colony social structure and immune defences of workers in the ant Formica selysi
}

\author{
G. Castella $\cdot$ P. Christe $\cdot$ M. Chapuisat
}

Received: 14 October 2009/Revised: 22 January 2010/ Accepted: 27 January 2010/Published online: 11 February 2010

(C) International Union for the Study of Social Insects (IUSSI) 2010

\begin{abstract}
Several ant species vary in the number of queens per colony, yet the causes and consequences of this variation remain poorly understood. In previous experiments, we found that Formica selysi workers originating from multiple-queen (=polygyne) colonies had a lower resistance to a fungal pathogen than workers originating from single-queen (=monogyne) colonies. In contrast, group diversity improved disease resistance in experimental colonies. This discrepancy between field and experimental colonies suggested that variation in social structure in the field had antagonistic effects on worker resistance, possibly through a down-regulation of the immune system balancing the positive effect of genetic diversity. Here, we examined if workers originating from field colonies with alternative social structure differed in three major components of their immune system. We found that workers from polygyne colonies had a lower bacterial growth inhibitory activity than workers from monogyne colonies. In contrast, workers from the two types of colonies did not differ significantly in bacterial cell wall lytic activity and prophenoloxidase activity. Overall, the presence of multiple queens in a colony correlated with a slight reduction in one inducible component of the immune system of individual workers. This reduced level of immune defence might explain the lower resistance of workers originating from polygyne colonies despite the positive effect of genetic diversity. More generally, these results indicate that social changes at the group level can modulate individual immune defences.
\end{abstract}

G. Castella $\cdot$ P. Christe $\cdot$ M. Chapuisat $(\bowtie)$

Department of Ecology and Evolution, Biophore, University of Lausanne, 1015 Lausanne, Switzerland e-mail: Michel.Chapuisat@unil.ch
Keywords Queen number · Polygyny · Immunity · Disease resistance $\cdot$ Social insects

\section{Introduction}

In social Hymenoptera, the number of reproducing individuals per colony is a labile trait that shapes many of the colony characteristics (Keller, 1993; Bourke and Franks, 1995). In ants, monogyne colonies, which are headed by a single queen and polygyne ones, which may contain up to several hundreds of queens, generally differ in demography, dispersal and mode of colony founding (Hölldobler and Wilson, 1990; Bourke and Franks, 1995). The multiple differences associated with social structure variation have been collectively referred to as the polygyny syndrome (Keller, 1993).

An interesting aspect of the polygyny syndrome is that the presence of multiple reproducing queens reduces the average relatedness between workers and the brood they rear, which bears an inclusive fitness cost to workers (Bourke and Franks, 1995). Conversely, polygyny increases intracolonial genetic diversity, which may in turn improve disease resistance (the "genetic diversity for disease resistance" hypothesis, Hamilton, 1987; Sherman et al., 1988) or colony homeostasis through a better division of labour among genetic specialists (Oldroyd and Fewell, 2007).

In a recent experiment, we have investigated whether increased group diversity improved disease resistance in the ant Formica selysi (Reber et al., 2008). This species is socially polymorphic, with monogyne and polygyne colonies coexisting in close proximity (Chapuisat et al., 2004). Increased group diversity obtained by experimentally mixing workers originating from monogyne field colonies 
improved the resistance to a fungal challenge with Metarhizium anisopliae (Reber et al., 2008). However, workers originating from polygyne field colonies had a lower survival than workers from monogyne field colonies, both in controls and when challenged with the fungal pathogen (Reber et al., 2008). These contrasting results suggest that a higher genetic diversity improves disease resistance, but that this effect is counterbalanced by other factors decreasing worker resistance in polygyne field colonies. In particular, changes in queen number might alter the investment in immune defences in such a way that workers from polygyne colonies would have reduced immune defences, as compared to workers from monogyne colonies.

In insects, immunity is mostly innate (Gillespie et al., 1997; Schmid-Hempel, 2005b; but see also Moret, 2006) and comprises fast-reacting constitutive components as well as slower and more specific inducible defences (Schmid-Hempel, 2005a; Haine et al., 2008). The intensity of immune defences shows much variation both within and across species (Schmid-Hempel, 2003). This variation can result from genetic (Ryder and Siva-Jothy, 2001; Cotter and Wilson, 2002) and environmental factors (Kurtz et al., 2002; Yourth et al., 2002). A wide array of environmental conditions may affect immunity, ranging from the risk of predation or parasitism to the accessibility or quality of food resources (Feder et al., 1997; Barnes and Siva-Jothy, 2000; Siva-Jothy and Thompson, 2002; Rantala et al., 2003; Joop and Rolff, 2004).

In social Hymenoptera, immune defences vary at both the individual and colony levels (Doums and SchmidHempel, 2000; Evans and Pettis, 2005; Baer and SchmidHempel, 2006; Decanini et al., 2007). Environmental, behavioural and life-history factors, such as diet, parasite exposure, nest environment, worker age or task specialization, influence the immune defences of workers (Doums and Schmid-Hempel, 2000; Amdam et al., 2005; Bocher et al., 2007; Castella et al., 2008; Simone et al., 2009). Individual variation in immune defences may in turn influence colony traits such as disease prevalence or colony productivity (Evans and Pettis, 2005). Conversely, social factors (Bocher et al., 2008) and colony traits such as colony size (Doums and Schmid-Hempel, 2000) and colony age (Moret and Schmid-Hempel, 2009) have been shown to affect individual immune defences. Variation in queen number per colony and its correlates may thus influence the immune defences of workers, but to our knowledge this has never been investigated so far.

Here, we examined if colony social structure correlated with variation in worker immune defences in the ant $F$. selysi. We sampled workers in monogyne and polygyne field colonies and measured three major components of their immune system, the bacterial growth inhibitory acti- vity, bacterial cell wall lytic activity and prophenoloxidase activity. We predicted that workers originating from monogyne colonies should have higher levels of immune defences than workers originating from polygyne colonies, because workers from monogyne colonies were more resistant to a fungal challenge (Reber et al., 2008), were significantly larger (Schwander et al., 2005) and represented a higher energetic investment for the colony (Rosset and Chapuisat, 2007). In addition, we also examined if the three components of the immune system varied significantly among colonies. Together these results will reveal if social or ecological variation at the colony level has an impact on the immune investment of individuals.

\section{Materials and methods}

\section{Sampling}

The ants were collected in a population of Formica selysi located between Sierre and Susten along the river Rhône in central Valais, Switzerland. We sampled workers from 19 monogyne colonies and 17 polygyne colonies. Detailed genetic data on colony social structure were obtained from the previous genotyping of $8-100$ individuals per colony at nine microsatellite markers (Chapuisat et al., 2004; Schwander et al., 2005; Reber et al., 2008). Twenty-five workers per colony were sampled on the top of the nests between October and November 2006 and placed in plastic boxes $(13.5 \times 15 \times 5 \mathrm{~cm})$ lined with Fluon to prevent ants from escaping. The ants were provided with food (obtained by mixing one chicken egg, $100 \mathrm{~g}$ of honey, $1 \mathrm{~g}$ of agar and $100 \mathrm{~g}$ of water) and distilled water. The workers were kept in the laboratory at $23^{\circ} \mathrm{C}$, with a $12 \mathrm{~h} / 12 \mathrm{~h}$ day/night cycle, and were prepared for immune measurements within the next 3 weeks.

\section{Immune measures}

We measured the individual immune defences of $19 \pm 3$ workers per colony, on average. We used worker homogenates, because the small size of workers precluded the reliable sampling of sufficient volumes of haemolymph. Workers were put in $0.5 \mathrm{ml}$ Eppendorf tubes and chilled on ice. The last three segments of the abdomen were removed, because they contain the poison gland and reservoir for formic acid (Hölldobler and Wilson, 1990). The head was also removed and kept apart for size measurement. The thorax and the remaining part of the abdomen were put in a tube containing $20 \mu \mathrm{l}$ of sodium cacodylate (Na-Cac $0.01 \mathrm{M} ; \mathrm{CaCl}_{2} 0.005 \mathrm{M}$ ) and squashed with a pellet pestle. The sample was then vortexed for $1 \mathrm{~min}$ and centrifuged at $6,600 \mathrm{rpm}$ for $15 \mathrm{~min}$ at $4^{\circ} \mathrm{C}$. Ten microlitres of the 
supernatant was collected and immediately frozen at $-80^{\circ} \mathrm{C}$

Bacterial growth inhibitory activity and bacterial cell wall lytic activity were measured with the inhibition zone and clearing zone assays, respectively (Castella et al., 2008, 2009; Moret and Schmid-Hempel, 2009). These two assays consist in depositing a small drop of homogenate solution on a culture medium. In the inhibition zone assay, the medium is seeded with live bacteria that, in the absence of inhibitor, grow to cover the entire surface. The inhibitory activity of the homogenate sample is estimated by measuring the mean diameter of the zone where bacterial growth has been inhibited. In the clearing zone assay, the medium contains bacterial cell walls extract and the lytic activity is estimated by measuring the mean diameter of the clear zone where cell walls have been lysed.

In the inhibition zone assay, we placed $2 \mu$ of the homogenate solution on the surface of a thin layer of L-Broth agar $(6 \mathrm{ml}$ in Petri dishes of $9 \mathrm{~cm}$ diameter; L-Broth agar contained $10 \mathrm{~g}$ of bactotryptone, $10 \mathrm{~g}$ of bacto-agar, $10 \mathrm{~g}$ of $\mathrm{NaCl}, 5 \mathrm{~g}$ of yeast extract and 1,000 ml distilled water, $\mathrm{pH}$ 7.5) mixed with the test bacteria Arthrobacter globiformis (Institut Pasteur Paris, nr. 81.84T) adjusted to $10^{5}$ cells $\mathrm{ml}^{-1}$. After overnight incubation at $30^{\circ} \mathrm{C}$, the minimum and maximum diameters of each zone of inhibition were measured on a digital picture using the ImageJ software (National Institutes of Health, Bethesda, MD, USA).

For the clearing zone assay, $2 \mu \mathrm{l}$ of the homogenate solution were placed on the surface of a thin layer of bactoagar $(5 \mathrm{ml}$ in lids of cell culture plates; agar contained $1 \mathrm{~g}$ of bacto-agar, $10 \mathrm{mg}$ of streptomycin sulphate and $2 \%$ of Triton X-100 in $100 \mathrm{ml}$ of distilled water) mixed with Micrococcus luteus cell walls extract (Sigma, $5 \mathrm{mg} \mathrm{ml}^{-1}$ ). After overnight incubation at $30^{\circ} \mathrm{C}$, the minimum and maximum diameters of each zone of lysis were measured on a digital picture using the ImageJ software (National Institutes of Health, Bethesda, MD, USA).

Prophenoloxidase (proPO) activity was measured as described by Moret and Siva-Jothy (2003), with slight modifications. The total amount of enzymes is proportional to the increase in optical density induced by the transformation of L-DOPA to dopachrome by phenoloxidase (Söderhäll and Cerenius, 1998). Samples were tested with a spectrophotometer for 96-well microplates (iEMS reader MF, Labsystem). Four microlitres of homogenate solution was mixed with $10 \mu \mathrm{l}$ of phosphate buffered saline (PBS) and $50 \mu \mathrm{l}$ of trypsin $(0.25 \%)$ in a microplate well and left for $5 \mathrm{~min}$ at room temperature. Trypsin proteolytically activates prophenoloxidase (the inactive form of the enzyme) into phenoloxidase (the active form), which results in a measure of the total enzymatic activity of the sample. Ten microlitres of L-DOPA ( $4 \mathrm{mg} \mathrm{ml}^{-1}$ ) was then added to the mix. The mixture absorbance at $492 \mathrm{~nm}$ was measured at $30^{\circ} \mathrm{C}$ every $10 \mathrm{~s}$ for $50 \mathrm{~min}$. The proPO activity was measured as the slope of the reaction curve during the linear phase of the reaction, expressed as the change in optical density $(\times 100)$ per second. Given the dilutions and units used, the phenoloxidase activity measured for individual workers ranged from 0 to 3.73, with a mean \pm SE of $2.46 \pm 0.10$ for the 20 workers with the highest activity. In contrast, no phenoloxidase activity was detected in the controls (mean \pm $\mathrm{SE}=0.000 \pm 0.000, n=33$ ).

\section{Worker size variation}

Head width was used to estimate worker size. This measure covaries isometrically with other body measures in Formica selysi (Schwander et al., 2005) and is commonly used as a dependent variable in studies of allometry in ants (Wheeler, 1991). Head widths were measured to the nearest $0.001 \mathrm{~mm}$ with a stereomicroscope Nikon Profile V-12 (Schwander et al., 2005). Overall, worker size varied significantly among colonies (one-way ANOVA, colony effect: $\left.F_{35,666}=14.61, P<0.0001\right)$. As shown previously (Schwander et al., 2005), workers originating from monogyne colonies were larger than workers from polygyne colonies (mean worker head width $\pm \mathrm{SE}: 1.30 \pm 0.01 \mathrm{~mm}$ for monogyne colonies and $1.19 \pm 0.01 \mathrm{~mm}$ for polygyne colonies; mixed ANOVA with social structure as fixed factor and colony as random factor: $F_{1,34.2}=35.75$, $P<0.0001)$.

Because we measured immunity on homogenates of thorax and abdomen in a fixed volume of buffer, we had to control for differences in the amount of tissue or haemolymph in the samples. We therefore normalized immune measures with respect to body size variation of workers. In effect, we divided the individual immune measure by the standardized size of the individual worker, which we calculated as the head width of the individual divided by the mean head width of all workers.

\section{Statistical analyses}

We compared the immunity of workers originating from monogyne and polygyne colonies with independent twosample $t$-tests (Student's $t$-tests or Welch's $t$-tests for unequal variance), using one mean value per colony. We tested whether workers' immunity varied among colonies with Kruskal-Wallis tests, using all individual values. All statistical analyses were performed with JMP 6.0 (SAS Institute Inc., Cary, NC, USA). 


\section{Results}

Covariation between social structure and worker immune system

Workers originating from polygyne colonies had a significantly lower bacterial growth inhibitory activity than workers originating from monogyne colonies $(t$-test: $t=$ -2.23 , d.f. $=32.2, P=0.03$, Fig. 1a). The social structure explained $12.3 \%$ of the variance in inhibitory activity among colonies. In contrast, the mean bacterial cell wall lytic activity and mean proPO activity of workers did not differ significantly between monogyne and polygyne colonies (lytic activity: $t=0.57$, d.f. $=21.9, P=0.58$, Fig. 1 b; proPO activity: $t=-0.42$, d.f. $=34, P=0.68$, Fig. 1c).

Immune system variation among colonies

The bacterial growth inhibitory activity and bacterial cell wall lytic activity of workers varied significantly among colonies (Table 1). The inhibitory activity of workers varied significantly among monogyne colonies, but not among polygyne colonies, indicating a larger variance for monogyne than polygyne colonies. The lytic activity of workers varied significantly among monogyne as well as among polygyne colonies. Finally, the level of proPO activity of individual workers did not vary significantly among colonies (Table 1).

\section{Discussion}

The transition from monogyny to polygyny is generally associated with major changes in dispersal, colony demography, nest density and relative investment in reproduction and maintenance (Hölldobler and Wilson, 1977; Keller, 1993; Rosset and Chapuisat, 2007). Such changes at the colony level may result in modifications of individual characteristics, including physiological traits. Here, we examined if variation in the social structure of $F$. selysi colonies was associated with changes in immune defences of workers.

The presence of multiple queens in field colonies was correlated with a slight reduction in one component of the immune system of individual workers. Indeed, workers originating from polygyne colonies had a significantly lower bacterial growth inhibitory activity than workers originating from monogyne colonies. In contrast, workers from the two types of colonies did not differ significantly in bacterial cell wall lytic activity and prophenoloxidase activity. Overall, these results suggest that workers from

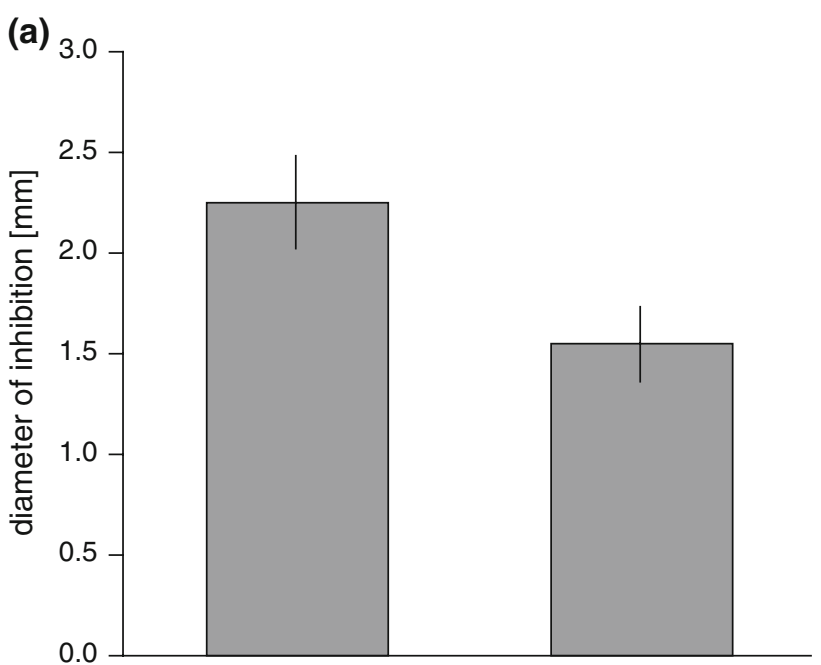

(b)

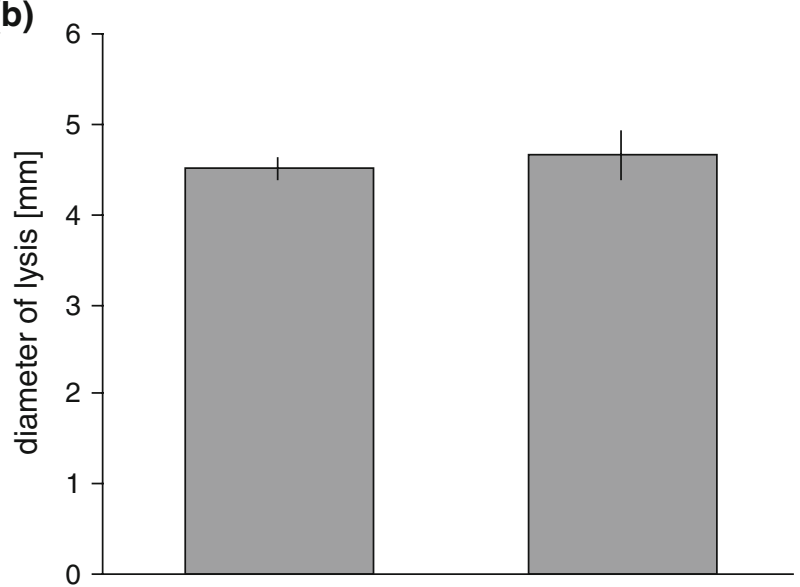

(c)

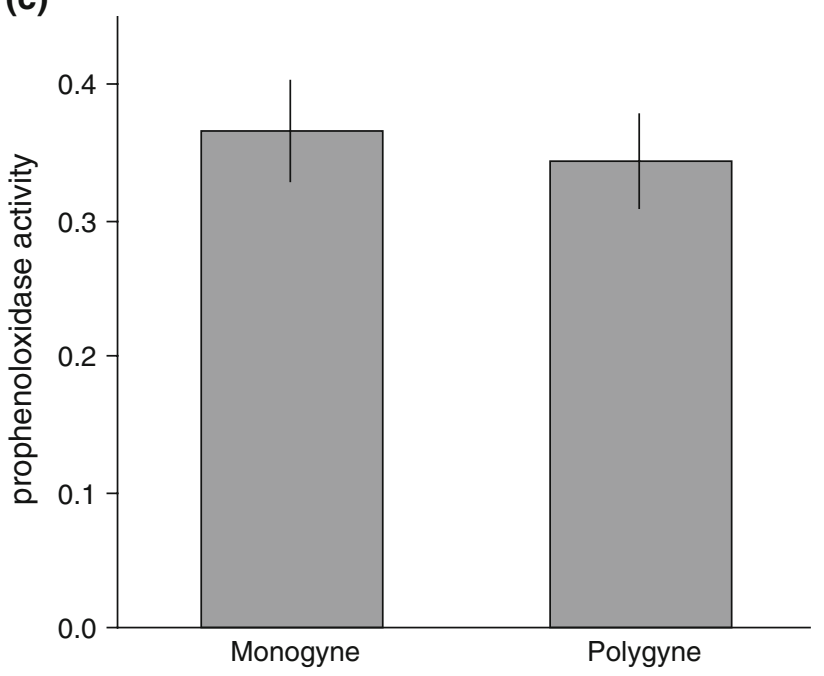

Fig. 1 Mean \pm SE of a bacterial growth inhibitory activity, b bacterial cell wall lytic activity and $\mathbf{c}$ prophenoloxidase activity of workers originating from monogyne $(n=19)$ and polygyne $(n=17)$ colonies. The immune measures were normalized with respect to body size variation of workers. One mean value was used per colony, averaging over $19 \pm 3$ workers per colony 
Table 1 Colony effect on workers' bacterial growth inhibitory activity, bacterial cell wall lytic activity and prophenoloxidase activity

\begin{tabular}{|c|c|c|c|c|c|c|c|c|c|}
\hline & \multicolumn{3}{|c|}{ All colonies } & \multicolumn{3}{|c|}{ Monogyne colonies } & \multicolumn{3}{|c|}{ Polygyne colonies } \\
\hline & d.f. & $\chi^{2}$ & $P$ & d.f. & $\chi^{2}$ & $P$ & d.f. & $\chi^{2}$ & $P$ \\
\hline Inhibitory activity & 35 & 58.8 & 0.007 & 18 & 32.6 & 0.02 & 16 & 17.5 & 0.35 \\
\hline Lytic activity & 35 & 125.7 & $<0.001$ & 18 & 48.7 & $<0.001$ & 16 & 46.5 & $<0.001$ \\
\hline Prophenoloxidase & 35 & 39.5 & 0.28 & 18 & 24.2 & 0.15 & 16 & 14.9 & 0.53 \\
\hline
\end{tabular}

Kruskal-Wallis tests were applied to all colonies irrespectively of their social structure, and to monogyne and polygyne colonies separately

polygyne field colonies are slightly less immunocompetent than workers from monogyne colonies, at least for some specific types of defence. This finding is in line with our previous experiments showing that workers sampled from polygyne field colonies had a lower resistance to a fungal challenge with M. anisopliae (Reber et al., 2008).

The inhibitory activity of worker homogenates can be due to multiple compounds, including antibacterial peptides in the haemolymph and secretions from exocrine glands (Gillespie et al., 1997; Poulsen et al., 2002). The production of antibacterial peptides is induced by bacterial or fungal infections (Gillespie et al., 1997). The higher inhibitory activity of workers originating from monogyne colonies might thus be due to a higher exposure to pathogens in this type of colonies, possibly because of differences in colony demography, colony size, or division of labour (Rosset and Chapuisat, 2007). Alternatively, the workers originating from monogyne colonies may be able to mount a comparatively higher immune response for the same level of pathogen exposure, possibly because their larger body size (Schwander et al., 2005; this study) and presumably higher energetic reserves allow them to invest relatively more in immune defence per unit of size.

The three components of the immune system differed in their pattern of variation among colonies. The bacterial growth inhibitory activity and bacterial cell wall lytic activity varied significantly among colonies. Both responses involve peptides that are synthesised by the insect fat body in order to combat infections by pathogenic microorganisms and this inducible response may last for several days or weeks (Boman and Hultmark, 1987; Gillespie et al., 1997; Schmid-Hempel, 2005a; Haine et al., 2008). Variation among colonies in inhibitory and lytic activities may thus in part reflect differences in their past exposure to parasites. Variation in inducible immune defences among colonies has also been documented in the honeybee Apis mellifera (Evans and Pettis, 2005) and the bumblebee Bombus terrestris (Doums and Schmid-Hempel, 2000).

In contrast, the level of prophenoloxidase in workers did not vary significantly among colonies. The prophenoloxidase is a constitutive zymogen which, once activated into phenoloxidase by proteolysis, leads to melanization (Gillespie et al., 1997). Our measures of phenoloxidase activity on workers homogenates were low and might have been reduced by the action of proteolytic digestive enzymes on prophenoloxidase or phenoloxidase. However, there was also no significant variation in phenoloxidase among colonies in the ant Cataglyphis velox (Bocher et al., 2007). Together, these results suggest that the amount of prophenoloxidase is a constitutive defence expressed at a similar baseline level across ant colonies.

This study revealed that some colony-level characteristics of $F$. selysi correlated with changes in specific components of the immune system of workers, whereas other components were unaffected. Overall, polygyny was associated with a slight decrease in the level of bacterial growth inhibitory activity of workers. This reduced investment in immune defences is consistent with the general pattern of allocation of resources to workers in polygyne colonies. Indeed, polygyne colonies tend to produce higher numbers of workers of lower quality, as indicated by their more populous colonies (Rosset and Chapuisat, 2007) composed of smaller workers (Schwander et al., 2005; this study) that had a lower resistance to a fungal challenge (Reber et al., 2008). More generally, our results suggest that social and environmental changes at the colony level affect the immune defences of individuals. The causal chain linking colony characteristics and specific components of the immune system of workers remains to be investigated. The observed covariation between queen number and immune defences might indeed be mediated by multiple factors, including differences in past exposure to pathogens, life-history or demography.

Acknowledgments We thank Céline Fioravanti and Antoine Burnier for their important contribution to this study during their undergraduate training, Yannick Moret for help with immunological techniques, Laurent Keller and an anonymous reviewer for comments on the manuscript. This research was supported by grants $3100 \mathrm{~A} 0$ 104118, 3100AO-108263 and 31003A_125306 from the Swiss National Science Foundation.

\section{References}

Amdam G.V., Aase A., Seehuus S.C., Fondrk M.K., Norberg K. and Hartfelder K. 2005. Social reversal of immunosenescence in honey bee workers. Exp. Gerontol. 40: 939-947 
Baer B. and Schmid-Hempel P. 2006. Phenotypic variation in male and worker encapsulation response in the bumblebee Bombus terrestris. Ecol. Entom. 31: 591-596

Barnes A.I. and Siva-Jothy M.T. 2000. Density-dependent prophylaxis in the mealworm beetle Tenebrio molitor (Coleoptera: Tenebrionidae): cuticular melanization is an indicator of investment in immunity. Proc. R. Soc. B. 267: 177-182

Bocher A., Tirard C. and Doums C. 2007. Phenotypic plasticity of immune defence linked with foraging activity in the ant Cataglyphis velox. J. Evol. Biol. 20: 2228-2234

Bocher A., Doums C., Millot L. and Tirard C. 2008. Reproductive conflicts affect labor and immune defense in the queenless ant Diacamma sp "nilgiri”. Evolution 62: 123-134

Boman H.G. and Hultmark D. 1987. Cell-free immunity in insects. Annu. Rev. Microbiol. 41: 103-126

Bourke A.F.G. and Franks N.R. 1995. Social Evolution in Ants. Princeton, NJ: Princeton University Press. $529 \mathrm{pp}$

Castella G., Christe P. and Chapuisat M. 2009. Mating triggers dynamic immune regulations in wood ant queens. J. Evol. Biol. 22: $564-570$

Castella G., Chapuisat M., Moret Y. and Christe P. 2008. The presence of conifer resin decreases the use of the immune system in wood ants. Ecol. Entom. 33: 408-412

Chapuisat M., Bocherens S. and Rosset H. 2004. Variable queen number in ant colonies: no impact on queen turnover, inbreeding, and population genetic differentiation in the ant Formica selysi. Evolution 58: 1064-1072

Cotter S.C. and Wilson K. 2002. Heritability of immune function in the caterpillar Spodoptera littoralis. Heredity 88: 229-234

Decanini L.I., Collins A.M. and Evans J.D. 2007. Variation and heritability in immune gene expression by diseased honeybees. J. Hered. 98: 195-201

Doums C. and Schmid-Hempel P. 2000. Immunocompetence in workers of a social insect, Bombus terrestris L., in relation to foraging activity and parasitic infection. Can. J. Zool. 78: 10601066

Evans J.D. and Pettis J.S. 2005. Colony-level impacts of immune responsiveness in honey bees, Apis mellifera. Evolution 59: 2270-2274

Feder D., Mello C.B., Garcia E.S. and Azambuja P. 1997. Immune responses in Rhodnius prolixus: Influence of nutrition and ecdysone. J. Insect Physiol. 43: 513-519

Gillespie J.P., Kanost M.R. and Trenczek T. 1997. Biological mediators of insect immunity. Annu. Rev. Entomol. 42: 611-643

Haine E.R., Moret Y., Siva-Jothy M.T. and Rolff J. 2008. Antimicrobial defense and persistent infection in insects. Science 322: 1257-1259

Hamilton W.D. 1987. Kinship, recognition, disease, and intelligence: constraints of social evolution. In: Animal Societies: Theories and Facts (Itô Y., Brown J.L. and Kikkawa J., Eds), Tokyo: Japan Scientific Societies Press. pp 81-102

Hölldobler B. and Wilson E.O. 1977. The number of queens: an important trait in ant evolution. Naturwissenschaften 64: 8-15

Hölldobler B. and Wilson E.O. 1990. The Ants. Cambridge: Harvard University Press. 732 pp

Joop G. and Rolff J. 2004. Plasticity of immune function and condition under the risk of predation and parasitism. Evol. Ecol. Res. 6: 1051-1062

Keller L. (Ed). 1993. Queen Number and Sociality in Insects. Oxford: Oxford University Press. $439 \mathrm{pp}$
Kurtz J., Klappert K., Schneider W. and Reinhold K. 2002. Immune defence, dispersal and local adaptation. Evol. Ecol. Res. 4: 431439

Moret Y. 2006. 'Trans-generational immune priming': specific enhancement of the antimicrobial immune response in the mealworm beetle, Tenebrio molitor. Proc. R. Soc. B. 273: 1399-1405

Moret Y. and Siva-Jothy M.T. 2003. Adaptive innate immunity? Responsive-mode prophylaxis in the mealworm beetle, Tenebrio molitor. Proc. R. Soc. B. 270: 2475-2480

Moret Y. and Schmid-Hempel P. 2009. Immune responses of bumblebee workers as a function of individual and colony age: senescence versus plastic adjustment of the immune function. Oikos 118: 371-378

Oldroyd B.P. and Fewell J.H. 2007. Genetic diversity promotes homeostasis in insect colonies. Trends Ecol. Evol. 22: 408-413

Poulsen M., Bot A.N.M., Nielsen M.G. and Boomsma J.J. 2002. Experimental evidence for the costs and hygienic significance of the antibiotic metapleural gland secretion in leaf-cutting ants. Behav. Ecol. Sociobiol. 52: 151-157

Rantala M.J., Kortet R., Kotiaho J.S., Vainikka A. and Suhonen J. 2003. Condition dependence of pheromones and immune function in the grain beetle Tenebrio molitor. Funct. Ecol. 17: 534-540

Reber A., Castella G., Christe P. and Chapuisat M. 2008. Experimentally increased group diversity improves disease resistance in ants. Ecol. Lett. 11: 682-689

Rosset H. and Chapuisat M. 2007. Alternative life-histories in a socially polymorphic ant. Evol. Ecol. 21: $577-588$

Ryder J.J. and Siva-Jothy M.T. 2001. Quantitative genetics of immune function and body size in the house cricket, Acheta domesticus. J. Evol. Biol. 14: 646-653

Schmid-Hempel P. 2003. Variation in immune defence as a question of evolutionary ecology. Proc. R. Soc. B. 270: 357-366

Schmid-Hempel P. 2005a. Evolutionary ecology of insect immune defenses. Annu. Rev. Entomol. 50: 529-551

Schmid-Hempel P. 2005b. Natural insect host-parasite systems show immune priming and specificity: puzzles to be solved. Bioessays 27: $1026-1034$

Schwander T., Rosset H. and Chapuisat M. 2005. Division of labour and worker size polymorphism in ant colonies: the impact of social and genetic factors. Behav. Ecol. Sociobiol. 59: 215-221

Sherman P.W., Seeley T.D. and Reeve H.K. 1988. Parasites, pathogens, and polyandry in social Hymenoptera. Am. Nat. 131: 602-610

Simone M., Evans J.D. and Spivak M. 2009. Resin collection and social immunity in honeybees. Evolution 63: 3016-3022

Siva-Jothy M.T. and Thompson J.J.W. 2002. Short-term nutrient deprivation affects immune function. Physiol. Entomol. 27: 206212

Söderhäll K. and Cerenius L. 1998. Role of the prophenoloxidaseactivating system in invertebrate immunity. Curr. Opin. Immunol. 10: $23-28$.

Wheeler D.E. 1991. The developmental basis of worker caste polymorphism in ants. Am. Nat. 138: 1218-1238

Yourth C.P., Forbes M.R. and Smith B.P. 2002. Immune expression in a damselfly is related to time of season, not to fluctuating asymmetry or host size. Ecol. Entom. 27: 123-128 